\title{
Right Posterosuperior Segment
}

National Cancer Institute

\section{Source}

National Cancer Institute. Right Posterosuperior Segment. NCI Thesaurus. Code C79738.

Couinaud segment VII, corresponding to the posterior segment of the right lobe of the liver, located superiorly. 